\title{
We welcome a new Managing Editor as we say farewell to Shannon
}

I would like to thank Shannon for her services as the Managing Editor for Powder Diffraction during the past three years. Shannon joined the ICDD staff in the PDF Editorial Department in 1995, was quickly promoted to Desktop Publishing Coordinator, and eventually became the Managing Editor of this journal in September 1999. She is a very hard worker, no task was ever too difficult for her, and she was always willing to help out. Many of the advertising designs of ICDD (such as the Clinic brochures and the Denver $\mathrm{X}$-ray Conference Call-for-Papers) are the result of Shannon's creativity and hard work. Without her, we would not have been able to roll out Powder Diffraction online. Late last year, she resigned as the Managing Editor. We wish her and her family the best. She will be missed.

We are delighted that Tim Jenkins has agreed to become our new Managing Editor starting 2003. Tim is the son of the late Dr. Ron Jenkins, who was the first Managing Editor of PD and one of its creators. Tim began with ICDD in January 2000 as the Bibliographic Coordinator with the responsibility of locating and retrieving the experimental patterns that are published in the PDF each year (except for Grants). He takes great pride in the quality of the journal his father helped create. We welcome Tim, and we look forward to working with him.
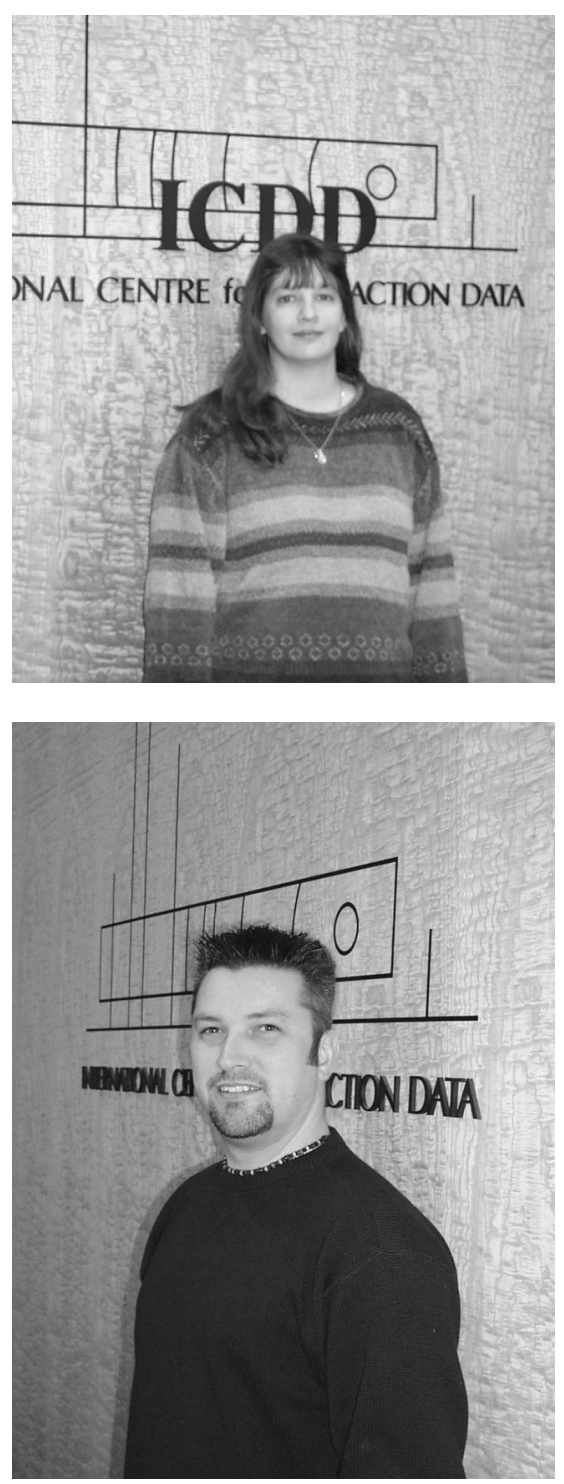